\title{
Reframing delusional infestation: perspectives on unresolved puzzles
}

This article was published in the following Dove Press journal: Psychology Research and Behavior Management

\author{
Jianbo Lai ${ }^{1-3}$ \\ Zhe $X u^{4,5}$ \\ Yi X ${ }^{1-3}$ \\ Shaohua $\mathrm{Hu}^{\mathrm{I}-3}$ \\ 'Department of Psychiatry, First \\ Affiliated Hospital, Zhejiang University \\ School of Medicine, Hangzhou \\ 310003, China; ${ }^{2}$ The Key Laboratory \\ of Mental Disorder's Management in \\ Zhejiang Province, Hangzhou 310003 , \\ China; ${ }^{3}$ Brain Research Institute \\ of Zhejiang University, Hangzhou \\ 310003, China; ${ }^{4} Z$ hejiang University \\ School of Medicine, Hangzhou 310003 , \\ China; ${ }^{5}$ Department of Psychiatry, \\ Third People's Hospital of Huzhou, \\ Hangzhou 3 I 3000 , China
}

\begin{abstract}
Delusional infestation (DI), a debilitating psychocutaneous condition, featured as a false fixed belief of being infested accompanied by somatosensory abnormality, behavior alteration, and cognitive impairment. Although management of primary causes and pharmacotherapy with antipsychotics and/or antidepressants can help to alleviate symptoms in most patients, the underlying etiology of DI still remains unclear. Morgellons disease (MD), characterized by the presence of cutaneous filaments projected from or embedded in skin, is also a polemic issue because of its relationship with spirochetal infection. This review aims to discuss the following topics that currently confuse our understandings of DI: 1) the relationship of real/sham "infestation" with DI/MD; 2) behavior alterations, such as self-inflicted trauma; 3) neuroimaging abnormality and disturbance in neurotransmitter systems; and 4) impaired insight in patients with this disease. In discussion, we try to propose a multifactorial approach to the final diagnosis of DI/MD. Future studies exploring the neurobiological etiology of DI/MD are warranted.
\end{abstract} Keywords: delusional infestation, Morgellons disease, behavior, neurotransmitter, insight

\section{Introduction}

Delusional infestation (DI) is an uncommon, intricate psychocutaneous condition. ${ }^{1}$ Against available medical evidence, patients with DI have a strong conviction that they are infested with little animals or less frequently inanimate matter. ${ }^{1,2}$ Meanwhile, patients always complain of abnormal skin sensations, such as stinging, biting, and crawling, which were ascribed to the "infestation". The symptoms of DI can occur as primary, or more commonly, secondary to diverse medical conditions, such as neuropsychiatric diseases, nutrient deficiency, psychotropic medications, infections, intoxication, tumors, and metabolic disturbance. ${ }^{3}$ Etiology-dependent management and antipsychotics/antidepressants have been reported to be therapeutically effective. ${ }^{1,3,4}$

Worldwide retrospective researches and case reports have painted an inexplicit epidemiological picture of DI. ${ }^{5-7}$ In clinical practice, DI might be underdiagnosed as patients are always reluctant to psychiatric referral and prefer to visit dermatologists, microbiologists, and general practitioners. The prevalence of appropriately 80 cases per million was reported in private practices, while much less cases were presented and identified in public health services (appropriately 5.5 cases per million). ${ }^{8}$ Middle-aged to elderly women, especially those with inadequate social contact, are more likely to be afflicted..$^{5-8}$ The duration of illness can be less than 1 year or as long as three decades. ${ }^{3}$ However, the final diagnosis and proper management of DI are always delayed.
Department of Psychiatry, First Affiliated Hospital, Zhejiang University School of Medicine, 79 Qingchun Road, Hangzhou 310003 , China

Tel/fax +86 57I 87235948

Email dorhushaohua@zju.edu.cn 
To date, there are still many puzzles hindering our indepth understanding of somatosensory abnormality, behavior alteration, and cognitive impairment in DI. 1) Are symptoms associated with DI simply delusional? Can real infestation cause DI-like symptoms? 2) How to unscramble the behavior pattern in DI patients, such as self-inflicted skin trauma? 3) Antipsychotics and/or antidepressants are generally effective in managing symptoms of DI. This phenomenon indicates disturbance in neurotransmitter systems according to the pharmacological actions of agents. Moreover, recent advances in neuroimaging researches of DI patients need to be updated, including brain anatomical and functional abnormalities. 4) Patients with DI commonly lost their insight of disease nature. Whether their insight can be restored after improvement in symptoms? A better characterizing of aforementioned puzzles is of significant importance in clinical practice and fundamental research.

Herein, we start with expounding the current knowledge of above puzzles. In the "Discussion" section, we try to propose a multifactorial approach, which helps to facilitate the diagnosis of DI/Morgellons disease (MD).

\section{Sham or real infestation}

This question should be prudently answered, as it directly determines the nature of DI. To date, a great many of animate pathogens have been blamed, including all kinds of arthropods, worms, bacteria, and fungi. ${ }^{8}$ These pathogens are always described as small and vivid. In contrast, inanimate matter, long and thin, such as fibers, threads, hair, and the like, is less frequently reported. ${ }^{9}$ A comprehensive review of different "pathogens" is listed in Figure $1 .{ }^{10-23}$ The specific

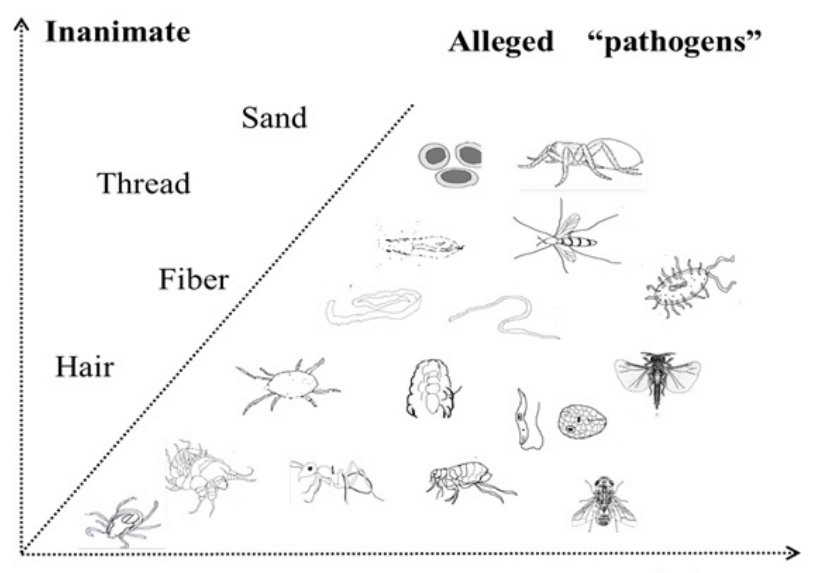

Animate

Figure I An atlas of alleged pathogens in patients with delusional infestation. Notes: In the animate group, schematic diagrams of black mold, lice, dust mite, Gongylonema pulchrum, scabies mite, worm, ant, flea, Leishmania, gnats, tick, fly, strepsiptera, spider, and bacteria are listed. In the inanimate group, fiber, thread, hair, and sand are listed. type of alleged pathogen by certain patient could be affected by one's own knowledge, life experience, and living environment. These pathogens might be wrapped with containers, referred to as the "specimen" or "matchbox" sign, ${ }^{3}$ and taken to clinic or hospital as an evidence of infestation. For most of the time, however, microscopy or even skin biopsy fails to find out the alleged pathogenic agent. In addition, the abnormal skin sensations, such as stinging, crawling, biting, and pinching, intensify patients' belief of infestation. In DI patients, abnormal activation of an itch pathway from the skin to the central nervous system is suspected. ${ }^{16}$ Dysfunction of interoception, improper processing, and misinterpretation of perceived sensations contribute to the formation of tactile or even visual hallucinations. Of note, it seems that delusions are always infestation oriented and, apart from infestation, the individuals' function well in other life scenes.

The closest diagnosis to DI in the Diagnostic and Statistical Manual of Mental Disorders, the fifth edition (DSM-5), is somatic-type delusional disorder. ${ }^{24}$ However, the diagnosis of delusional disorder should be exclusive, that is, the disturbance cannot be better explained by any substance, underlying mental comorbidities and psychical conditions. ${ }^{24}$ Within this framework, most DI cases reported in literatures are secondary, not primary, and therefore could not be diagnosed as somatic-type delusional disorder. Whatever, we should first determine whether the belief is delusional or not.

MD, characterized as embedded or protruding filaments in skin lesions, was once considered as a variation of DI by some researchers., ${ }^{3,9}$ However, other researchers have claimed an infectious process underlying this disease. The presentation of specimen, which is further confirmed as cutaneous filaments, may not be delusional in some cases. They reported positive tests of Borrelia spirochetes in patients with MD. ${ }^{22,23}$ In these studies, the researchers found that patients with MD shared similar systematic symptoms (eg, skin irritation, fatigue, joint pain, cardiac complications, and cognitive deficits) to those with tick-borne illnesses, for example, Lyme disease. ${ }^{25}$ They reported that the major components of MD cutaneous filaments were keratin and collagen, which were produced by keratinocytes and fibroblasts. ${ }^{25}$ The formation of these filaments could be resulted from skin proliferation in underlying infectious process. Treatment of MD patients seems to be more challenging than those with DI patients. ${ }^{26,27}$ Therefore, MD seems more likely to be a discrete entity, rather than a variation of DI. Some studies against the infectious cause of MD have also been published. In the Pearson study, for instance, researchers did not found any link between MD and Lyme disease. ${ }^{28}$ The histopathologic abnormality of 
skin samples was most likely to be solar elastosis, and most of the materials presented by the patients were composed of cellulose, compatible with cotton fibers. ${ }^{28}$ However, the Pearson study selected patients via a retrospective review of medical records. The inclusion criteria in this study did not strictly require the presentation of embedded or protruding skin fibers. The patients were a heterogeneous group, and the fiber analysis was conducted in a small number of patients. ${ }^{25,28}$

Notably, neither MD nor DI is listed in DSM-5. Tests for Lyme disease are insensitive, which complicate the diagnosis. The use of techniques, such as immunostaining and PCR, to directly detect spirochetal pathogens in skin is needed. Moreover, the skin lesions caused by self-mutilation behaviors may result in secondary infection, which further complicates this condition. Based on current findings, MD is not a subtype of DI and its interplay with spirochetal infection needs further investigations.

\section{Alterations in behavioral characteristics}

Health-related quality of life was significantly reduced in DI patients. Individuals without this condition can hardly imagine the encounters of afflicted patients. These patients always isolate themselves and present altered behavioral characteristics, which can be typically classified into two patterns, outward and inward. A common explanation for these behaviors is to find out and eradicate the putative pathogens. Another reason could be a way to release anxiety and stress. However, negative medical findings and vain self-inflicted attempts, eventually result in a vicious circle, which promotes the persistence of disease and increases the severity of symptoms.

\section{The outward pattern}

1) Patients repetitively seek help from many doctors of different specialties and are prescribed with antibiotic, virucide, pesticide, or other anti-infectives. ${ }^{15,29}$ The effect of these medications is always unsatisfactory and sometimes detrimental, causing skin irritation and abnormal sensations similar to skin complaints of DI, as well as nausea, headache, diarrhea, fatigue, and even elevated liver enzymes. ${ }^{15}$ 2) In cases of DI by proxy, especially patients with children living together, precautionary protection of children from excessive cleansing is particularly important. ${ }^{30}$ Similar condition is that pet owners hold a fixed, but false belief that their pets have been infested and need veterinary treatments. ${ }^{31,32} 3$ ) A increased risk of drug abuse was observed in DI patients, which would worsen their conditions. ${ }^{5}$ However, the causes for this phenomenon is unclear and may relate to physical or psychiatric comorbidities. In the outward pattern, patients focus on the surroundings rather than their own body.

\section{The inward pattern}

1) Self-inflicted skin trauma caused by mechanical force or fingernails is thought to target the causative pathogen and relieve skin discomfort. ${ }^{12,33}$ 2) Self-therapy with different chemicals or physical strategies aims to kill or flush away the pathogens from the body. ${ }^{3,34} 3$ ) Repetitive and intensive self-cleaning with an obsessive trait, such as frequent changing of clothes and hair washing, reflects excessive fear of contamination. ${ }^{35} 4$ ) In addition, comorbidity with psychiatric diseases or depression, secondary to DI, is associated with increased proneness to suicidal ideations and attempts. ${ }^{36}$ These inward behaviors are exhaustive, frustrated, and even detrimental and are generally more convenient to be implemented than outward behaviors.

The abnormal behaviors in DI patients are associated with their loss of disease insight. The skin lesions secondary to self-mutilation, eg, ulcerations, erosions, and pigmentations, can worsen the condition and sometimes were perceived as evidence of infestation., ${ }^{3,35}$ Apparently, these patients have difficulties in decision making and risk evaluation of their behaviors. ${ }^{37}$ In general, abnormal behavioral patterns, accompanied with personality alteration, are adaptive to the anxiety and fear caused by uncomfortable skin sensations and hallucinations. Alterations in behaviors, in turn, may also consolidate the skin discomfort.

\section{Updates on the neural correlates of DI}

To date, the neural mechanisms of DI remain largely unknown. Many DI cases are secondary to various medical conditions, which make the issue more complicated. The role of genetic vulnerability and neurodevelopmental or neuroimmune aberration has been inadequately investigated. However, disturbance in brain neurotransmitter systems is evident since many cases of DI respond well to antipsychotic or antidepressant treatment. Recent neuroimaging findings of DI also need to be updated.

\section{Imbalance in neurotransmitter systems}

A comprehensive review of drugs that can elicit or otherwise treat DI is presented in Table $1 .^{13,38-60}$ Accordingly, several lines of dysfunction in neurotransmitter systems are revealed. Except for the well-known hyperactivity in dopamine system, dysfunction in serotonergic neurotransmission and adrenergic neurotransmission, as well as the histamine and 
Table I Drugs potential to elicit or treat DI

\begin{tabular}{|c|c|c|}
\hline & Neuropharmacological targets & References \\
\hline \multicolumn{3}{|c|}{ Drugs potential to elicit DI } \\
\hline Cocaine & $\begin{array}{l}\text { I. Blockade of DAT protein } \\
\text { 2. } 5-\mathrm{HT}_{3} \text { receptor antagonist } \\
\text { 3. } 5-\mathrm{HT}_{2 \mathrm{~A}} \text { and } 5-\mathrm{HT}_{2 \mathrm{C}} \text { receptors' agonist }\end{array}$ & 38 \\
\hline Pemoline & I. D surrogate & 39 \\
\hline Amphetamine & $\begin{array}{l}\text { 2. Blockade of DAT protein and a releasing effect of D } \\
\text { 3. Blockade of NET protein and a releasing effect of NE } \\
\text { 4. } 5-\mathrm{HT}_{\perp A} \text { receptor antagonist }\end{array}$ & 40 \\
\hline Methylphenidate & $\begin{array}{l}\text { I. Blockade of DAT protein } \\
\text { 2. Blockade of NET protein } \\
\text { 3. Sigma-I receptor agonist }\end{array}$ & 41 \\
\hline Donepezil & I. Reversible cholinesterase inhibitor & 42 \\
\hline Piribedil & $\begin{array}{l}\text { 2. } D_{2} \text { and } D_{3} \text { receptors' agonist } \\
\text { 3. } \alpha_{2} \text { adrenergic receptor antagonist }\end{array}$ & 43 \\
\hline Phenelzine & $\begin{array}{l}\text { I. Nonselective and irreversible MAOI } \\
\text { 2. Inhibitors of ALT and GABA-T proteins } \\
\text { 3. Its metabolite, phenethylamine, has a releasing effect of NE and D }\end{array}$ & 44 \\
\hline \multicolumn{3}{|c|}{ Drugs used to treat DI } \\
\hline \multicolumn{3}{|c|}{ First generation antipsychotics } \\
\hline Pimozide & $\begin{array}{l}\text { I. } D_{2}, D_{3} \text {, and } D_{4} \text { receptors' antagonist } \\
\text { 2. } 5-H_{7} \text { receptor antagonist }\end{array}$ & 45 \\
\hline Haloperidol & $\begin{array}{l}\text { I. } D_{2}, D_{3} \text {, and } D_{4} \text { receptors' antagonist } \\
\text { 2. } \alpha_{1 A} \text { adrenergic receptors' antagonist } \\
\text { 3. Irreversible sigma-I receptor antagonist }\end{array}$ & 46 \\
\hline Trifluoperazine & $\begin{array}{l}\text { I. } D_{1} \text { and } D_{2} \text { receptors' antagonist } \\
\text { 2. Antiadrenergic and mild anticholinergic effects }\end{array}$ & 47 \\
\hline Chlorpromazine & $\begin{array}{l}\text { I. } D_{1}, D_{2}, D_{3} \text {, and } D_{4} \text { receptors' antagonist } \\
\text { 2. 5-HT, and 5-HT } T_{2} \text { receptors' antagonist } \\
\text { 3. } \alpha_{1} \text { and } \alpha_{2} \text { adrenergic receptors' antagonist } \\
\text { 4. } H_{1} \text { receptor antagonist } \\
\text { 5. } M_{1} \text { and } M_{2} \text { receptors antagonist }\end{array}$ & 47 \\
\hline \multicolumn{3}{|c|}{ Second generation antipsychotics } \\
\hline Clozapine & $\begin{array}{l}\text { I. 5-HT } \mathrm{HA}_{2 \mathrm{~A}}, 5-\mathrm{HT}_{2 \mathrm{~B}} \text {, and } 5-\mathrm{HT}_{2 \mathrm{C}} \text { receptors' antagonist } \\
\text { 2. } \mathrm{D}_{2} \text { and } \mathrm{D}_{4} \text { receptors' partial agonist } \\
\text { 3. Serotonin } 5-\mathrm{HT}_{1 \mathrm{~A}} \text { partial agonist } \\
\text { 4. } \alpha_{1} \text { and } \alpha_{2} \text { adrenergic receptors' antagonist } \\
\text { 5. } \mathrm{H}_{1} \text { receptor antagonist } \\
\text { 6. } \mathrm{GABA}_{\mathrm{B}} \text { receptor antagonist }\end{array}$ & 48 \\
\hline Olanzapine & $\begin{array}{l}\text { I. } 5-\mathrm{HT}_{2 \mathrm{~A}}, 5-\mathrm{HT}_{2 \mathrm{~B}} \text {, and } 5-\mathrm{HT}_{2 \mathrm{C}} \text { receptors' antagonist } \\
\text { 2. } \mathrm{D}_{2} \text { receptor antagonist } \\
\text { 3. } \mathrm{H}_{1} \text { receptor inverse agonist } \\
\text { 4. } \alpha_{1} \text { and } \alpha_{2} \text { adrenergic receptors' antagonist } \\
\text { 5. } \mathrm{M}_{1} \text { and } \mathrm{M}_{3} \text { receptors' antagonist }\end{array}$ & 49,50 \\
\hline Quetiapine & $\begin{array}{l}\text { I. } 5-H T_{2 A} \text { and } 5-H T_{2 C} \text { receptors' antagonist } \\
\text { 2. 5-HT } T_{1 A} \text { receptor partial agonist } \\
\text { 3. } D_{1}, D_{2}, D_{3} \text {, and } D_{4} \text { receptors' antagonist } \\
\text { 4. } \alpha_{1} \text { and } \alpha_{2} \text { adrenergic receptors' antagonist } \\
\text { 5. } H_{1} \text { receptor inverse agonist }\end{array}$ & 50 \\
\hline Blonanserin & $\begin{array}{l}\text { I. } \mathrm{D}_{2} \text { receptor antagonist } \\
\text { 2. } 5-\mathrm{HT}_{2} \text { receptor antagonist } \\
\text { 3. } \alpha_{1} \text { adrenergic receptor antagonist } \\
\text { 4. Low affinity for the sigma receptor }\end{array}$ & 51 \\
\hline Aripiprazole & $\begin{array}{l}\text { I. } \mathrm{D}_{2} \text { and } \mathrm{D}_{3} \text { receptors' partial agonist } \\
\text { 2. } 5-\mathrm{HT}_{1 \mathrm{~A}} \text { and } 5-\mathrm{HT}_{2 \mathrm{C}} \text { receptors' partial agonist } \\
\text { 3. } 5-\mathrm{HT} \mathrm{T}_{1 \mathrm{~A}} \text { receptor antagonist } \\
\text { 4. Moderate affinity for histamine, } \alpha \text {-adrenergic receptors }\end{array}$ & 52,53 \\
\hline
\end{tabular}


Table I (Continued)

\begin{tabular}{|c|c|c|}
\hline & Neuropharmacological targets & References \\
\hline Risperidone & $\begin{array}{l}\text { I. } D_{1}, D_{2}, D_{3} \text {, and } D_{4} \text { receptors' antagonist } \\
\text { 2. } 5-H T_{1 A}, 5-H T_{2 B} \text {, and } 5-H T_{2 C} \text { receptors' inverse agonist } \\
\text { 3. } \alpha_{1} \text { and } \alpha_{2} \text { adrenergic receptors' antagonist } \\
\text { 4. } H_{1} \text { receptor inverse agonist }\end{array}$ & 50 \\
\hline Paliperidone & $\begin{array}{l}\text { 1. } \alpha_{1} \text { and } \alpha_{2} \text { adrenergic receptors' antagonist } \\
\text { 2. } H_{1} \text { receptor antagonist } \\
\text { 3. } \mathrm{D}_{2} \text {, receptor antagonist } \\
\text { 4. 5-HT } \mathrm{T}_{2 \mathrm{~A}} \text { receptor antagonist }\end{array}$ & 54,55 \\
\hline Ziprasidone & $\begin{array}{l}\text { I. } D_{1}, D_{2}, D_{3} \text {, and } D_{4} \text { receptors' antagonist } \\
\text { 2. } 5-H T_{1 A} \text { and } 5-H T_{1 B} \text { receptors' partial agonist } \\
\text { 3. } 5-H T_{2 A}, 5-H T_{2 B} \text {, and } 5-H T_{2 C} \text { receptors' antagonist } \\
\text { 4. } \alpha \mathrm{I} \text {-adrenergic receptor antagonist } \\
\text { 5. Blockade of } S E R T \text { and NET proteins } \\
\text { 6. Moderate affinity for } H_{1} \text { receptor }\end{array}$ & 56 \\
\hline \multicolumn{3}{|l|}{ Antidepressants } \\
\hline Paroxetine & $\begin{array}{l}\text { I. Blockade of SERT, NET, and DAT proteins } \\
\text { 2. } M_{1} M_{2}, M_{3} \text {, and } M_{4} \text { receptors' antagonist }\end{array}$ & 57 \\
\hline Citalopram & I. Blockade of SERT protein & 48,58 \\
\hline Milnacipran & I. Blockade of SERT and NET proteins & 59 \\
\hline \multicolumn{3}{|l|}{ Other drugs } \\
\hline Gabapentin + antidepressant & GABA analog & 60 \\
\hline
\end{tabular}

Abbreviations: ALT, alanine transaminase; D, dopamine; DAT, D transporter; DI, delusional infestation; GABA, gamma-aminobutyric acid; GABA-T, GABA transaminase; $\mathrm{H}$, histamine; 5-HT, serotonin; M, muscarinic; MAOI, monoamine oxidase inhibitor; NE, norepinephrine; NET, NE transporter; SERT, serotonin transporter.

gamma-aminobutyric acid circuits, should also be noted. These findings indicate a complicated biological underpinning of DI. First, different neurotransmitter pathways are involved and provide possible explanations for the diverse symptom spectrums of DI, eg, tactile hallucination, delusion, behavior, affect, and cognitive alterations. Second, these neurotransmitter pathways are interconnected and their interactions may contribute to the onset of DI. Third, not only neurotransmitter receptors but also their transporters and various enzymes appear to be neuropharmacological targets of drugs listed in Table 1. Therefore, the pharmacotherapy for DI patients should be established on the symptomatic features, past treatment responses, and adverse effects of medications.

\section{Advances in neuroimaging studies}

Early studies have demonstrated cortical and subcortical atrophy in DI patients, including thalamus, striatum/ putamen, and fronto-temporo-parietal network. ${ }^{3,61}$ Using surface-based analysis, DI patients were reported to have increased cortical thickness in the right medial orbitofrontal cortex, reduced surface area in the left inferior temporal gyrus, the pars orbitalis of the right frontal gyrus, the lingual gyrus, and the precuneus, and lower local gyrification index in the left postcentral, bilateral precentral, right middle temporal, inferior parietal, and superior parietal gyri. ${ }^{62}$ These brain areas are associated with sensory perception, visuospatial control, and self-awareness. A recent multimodal study has confirmed the fronto-temporo-parietal network in mediating the core DI symptoms and revealed the possible functional pathway of antipsychotics on DI by blocking striatum $\mathrm{D}_{2}$ receptors ${ }^{63}$ Regardless of their etiology, different cases of DI seem to share similar pattern of gray matter volume change in brain regions, such as frontal, temporal, parietal, insular lobes, thalamus, and striatum. ${ }^{64}$ With a combination of functional MRI and an infestationrelevant visual task, a more recent study has highlighted fronto-limbic dysfunction within insula, amygdala, and prefrontal lobe, which is associated with differences in self-representation. ${ }^{65}$ The findings were overlapped in these studies, and neuroimaging abnormalities in brain regions, such as thalamus, striatum/putamen, and insula, have been repetitively documented.$^{66}$ The dysfunction in sensorimotor and peripersonal networks may possibly explain the somatic delusions in DI patients. ${ }^{66}$

However, the alterations in certain brain regions may result from infections, such as spirochetal infection, either via direct cerebral invasion or via immune pathways in susceptible individuals. Moreover, it is still unknown that the neurological changes in DI patients are reversible or persistent after symptom remission. 


\section{Insight}

Insight of disease nature is an important indicator of disease severity. Self-destructive behaviors in DI patients are considered to correlate with a loss of disease insight. Indeed, many patients are reluctant to psychiatric referrals and antipsychotics/antidepressants. It is the satisfactory efficacy of psychotropic agents that make them to believe it might be the right way to solve their problems. However, little attention has been paid to the restoration of insight after symptom remission.

According to an observational study, symptom recurrence is common in DI patients when treatment is discontinued. ${ }^{67}$ This phenomenon reflects that at least a subgroup of DI population is intractable and their temporal response to pharmacotherapy does not equal to full restoration of disease insight. In fact, despite the salient treatment efficacy, some patients may spontaneously stop taking psychotropic agents. It has been reported that the side effects of these drugs are the main reason for their nonadherence to medications. ${ }^{68}$ However, similar to other studies, this study also neglected the role of impaired insight on this issue.

Herein, we believe that the insight deficits in DI patients merit more attention. Partial or complete lack of insight will delay the diagnosis and impair treatment outcome, adherence to medications, and long-term functioning improvement. Physicians should focus not only on the remission in clinical symptoms but also on the patients' understanding of their sufferings and medications. Therefore, long-term follow-up is of great importance for DI patients after symptom remission.

\section{Discussion}

In this article, we put forward some unresolved puzzles and debates of DI/MD and discuss them based on the recent findings. The etiology of DI is possibly multifactorial as many DI cases are secondary to various medical conditions. The closest diagnosis to DI in DSM-5 is somatic-type delusional disorder. However, only the primary type of DI met the diagnostic criteria of this delusional disorder. MD is a similar condition to DI, but its relationship with tick-borne illnesses has been supported by a series of studies. DI patients have characteristic alterations in behavior pattern that could result from abnormal skin sensations, emotional anxiety, and stress. The disrupted behaviors are enhanced in a vicious circle because of failure to eliminate the alleged pathogens. Herein, for the first time, we put forward the concepts of inward and outward patterns of behaviors. Different case reports have demonstrated that a series of psychotropic agents are effective for treating DI. However, no well-designed clinical studies have ever verified the efficacy of these agents.
The disturbance of various neurotransmitter systems again indicates the complexity of DI. Neuroimaging findings are in part consistent among different studies with different designs. The abnormal brain areas are involved in neural circuits associated with self-awareness, self-representation, visuospatial control, and sensory perception. The relationship between neurological changes and spirochetal infection needs more investigation. Patients with DI have deficits in disease insight, and their insight may fail to be fully restored after remission in symptoms. The insight in DI patients calls for more attention because it affects the timely diagnosis, treatment adherence, and long-term outcome.

The onset of DI depends on various factors, including genetic susceptibility, personality traits, life experience, and primary medical conditions. The intensification and maintenance of DI symptoms are influenced by unquenched environment stimuli, brain structural and functional alterations, and untreated primary diseases. The diagnosis and treatment of DI patients should be individualized and evidence based. As for a specific patient, the diagnosis of primary DI could be made only after ruling out other possible causes. However, the definition or inclusion criteria for DI/MD vary among previous studies. To facilitate the diagnosis of DI/MD in clinical practice, we herein try to propose a multifactorial approach as follows.

The first step needs to determine whether delusion exists or not. A delusion is defined as a firmly, but false belief held with strong conviction and contrary to the superior evidence. It is distinct from beliefs based on an unusual perception, such as formication. The beliefs that patients hold could be delusion, true observations, or overvalued ideas. This must be determined on a case-by-case basis. The presentation of a specimen is not a delusional behavior. Patients with DI/MD with animate or inanimate objects can exist, but the belief of cutaneous fibers may or may not be delusional. A physician is required to perform fiber analysis to identify the nature of fibers. If fibers are present and biofilaments of human origin, then they are a true observation. It is also possible that patients might observe fibers and mistake them for worms in which case the idea of infestation could be an overvalued idea. Real infestation with arthropods such as mites can also occur. Additionally, some patients could have lesions with adhering textile fibers that are accidental contaminants and could mistakenly believe that they have MD, in which case they do not have a delusional belief, but a mistaken belief. In summary, if a physician cannot differentiate between true observations, delusions, and overvalued ideas, they should not immediately make a diagnosis of delusional mental illness. 
The next procedure would be screening the causes of the symptoms. If a delusional belief is present, then various medical conditions need to be ruled out, including psychiatric disorders (eg, schizophrenia and depression), neurological illnesses (eg, dementia), metabolic illnesses (eg, diabetes), vitamin deficiencies, substance intoxication, tumor, dermatological illnesses (eg, pruritus senilis), and infection. History taking, physical examination, laboratory tests, and even skin biopsy should be carried out. The diagnosis of DI could be classified as primary and secondary. If there are cutaneous fibers present and the belief is not delusional, the underlying cause of the symptoms, such as potential infection, should be examined. A diagnosis of MD is more convincing when spirochetal infection is identified. If a patient has delusional beliefs and has cutaneous fibers, then testing of an underlying infection that can result in neuropathy is needed.

\section{Conclusion}

The relationship between DI/MD and infestation, the abnormal behavior pattern, the disrupted brain function and structure, and disease insight have been discussed in this article. Clinical diagnosis of DI/MD should be stepwise, and interdisciplinary examinations of underlying causes are needed. Future studies on DI/MD, especially the neurobiological mechanisms, are warranted.

\section{Acknowledgments}

This work was supported by the grants of the National Key Research and Development Program (2016YFC1307100 and 2016YFC1307102), the Public Welfare Project of Science Technology Department of Zhejiang Province (2015C33133), the National Science and Technology Program (2015BAI13B02), and the Key Research Project of Zhejiang Province (2015C03040).

\section{Disclosure}

The authors report no conflicts of interest in this work.

\section{References}

1. Koo J, Lee CS. Delusions of parasitosis. A dermatologist's guide to diagnosis and treatment. Am J Clin Dermatol. 2001;2(5):285-290.

2. Bewley AP, Lepping P, Freudenmann RW, Freundenmann RW, Taylor R. Delusional parasitosis: time to call it delusional infestation. $\mathrm{Br} J$ Dermatol. 2010;163(1):1-2.

3. Freudenmann RW, Lepping P. Delusional infestation. Clin Microbiol Rev. 2009;22(4):690-732.

4. Heller MM, Wong JW, Lee ES, et al. Delusional infestations: clinical presentation, diagnosis and treatment. Int J Dermatol. 2013;52(7):775-783.

5. Foster AA, Hylwa SA, Bury JE, et al. Delusional infestation: clinical presentation in 147 patients seen at Mayo Clinic. JAm Acad Dermatol. 2012;67(4):673.e1-10.
6. Freudenmann RW, Lepping P, Huber M, et al. Delusional infestation and the specimen sign: a European multicentre study in 148 consecutive cases. Br J Dermatol. 2012;167(2):247-251.

7. Bailey CH, Andersen LK, Lowe GC, et al. A population-based study of the incidence of delusional infestation in Olmsted County, Minnesota, 1976-2010. Br J Dermatol. 2014;170(5):1130-1135.

8. Trabert W. Delusional parasitosis. Studies on frequency, classification and prognosis [Dissertation]. Universita"t des Saarlandes, Homburg/ Saar, Germany; 1993.

9. Harth W, Hermes B, Freudenmann RW. Morgellons in dermatology. J Dtsch Dermatol Ges. 2010;8(4):234-242.

10. Lewis AS, Oldham MA. Delusional Infestation With Black Mold Presenting to the General Hospital. Prim Care Companion CNS Disord. 2015;17(2).

11. Sawant NS, Vispute CD. Delusional parasitosis with folie à deux: A case series. Ind Psychiatry J. 2015;24(1):97-98.

12. Beach SR, Kroshinsky D, Kontos N. Case records of the Massachusetts General Hospital. Case 37-2014. A 35-year-old woman with suspected mite infestation. N Engl J Med. 2014;371(22):2115-2123.

13. Stanciu CN, Penders TM, Oxentine HN. Delusional infestation following misuse of prescription stimulants. Psychosomatics. 2015;56(2):210-212.

14. Battistelli-Lux C. Buccal infection with Gongylonema pulchrum: an indigenous case in France. Ann Dermatol Venereol. 2013;140(10):623-627.

15. Tran MM, Iredell JR, Packham DR, O’Sullivan MV, Hudson BJ. Delusional infestation: an Australian multicentre study of 23 consecutive cases. Intern Med J. 2015;45(4):454-456.

16. Kimsey LS. Delusional Infestation and Chronic Pruritus: A Review. Acta Derm Venereol. 2016;96(3):298-302.

17. Hopkinson G. Delusions of infestation. Acta Psychiatr Scand. 1970;46(2): 111-119.

18. Wilhelmi J. Ungezieferwahn. Med Welt. 1935;9:351-354.

19. Schwarz, Dr. H. Zirkumskripte Hypochondrien. Eur Neurol. 1929;72(2-3):150-164.

20. Freudenmann RW. A case of delusional parasitosis in severe heart failure. Olanzapine within the framework of a multimodal therapy. Nervenarzt. 2003;74(7):591-595.

21. Harbauer H. Das Syndrom des "Dermatozoenwahns" (Ekbom). Nervenarzt. 1949;20:254-258.

22. Middelveen MJ, Burugu D, Poruri A, et al. Association of spirochetal infection with Morgellons disease. F1000Res. 2013;2:25.

23. Middelveen MJ, Bandoski C, Burke J, et al. Exploring the association between Morgellons disease and Lyme disease: identification of Borrelia burgdorferi in Morgellons disease patients. BMC Dermatol. 2015;15:1.

24. American Psychiatric Association. Diagnostic and Statistical Manual of Mental Disorders. 5th ed. St Louis: APA; 2016.

25. Middelveen MJ, Fesler MC, Stricker RB. History of Morgellons disease: from delusion to definition. Clin Cosmet Investig Dermatol. 2018;11:71-90.

26. Dewan P, Miller J, Musters C, Taylor RE, Bewley AP. Delusional infestation with unusual pathogens: a report of three cases. Clin Exp Dermatol. 2011;36(7):745-748.

27. Sandhu RK, Steele EA. Morgellons Disease Presenting As an Eyelid Lesion. Ophthal Plast Reconstr Surg. 2014 Epub ahead of print.

28. Pearson ML, Selby JV, Katz KA, et al. Clinical, epidemiologic, histopathologic and molecular features of an unexplained dermopathy. PLoS One. 2012;7(1):e29908.

29. Freudenmann RW. [Delusions of parasitosis: an up-to-date review]. Fortschr Neurol Psychiatr. 2002;70(10):531-541. German [with English abstract]

30. Ahmed H, Blakeway EA, Taylor RE, Bewley AP. Children with a mother with delusional infestation--implications for child protection and management. Pediatr Dermatol. 2015;32(3):397-400.

31. Lepping P, Rishniw M, Freudenmann RW. Frequency of delusional infestation by proxy and double delusional infestation in veterinary practice: observational study. Br J Psychiatry. 2015;206(2):160-163. 
32. Rishniw M, Lepping P, Freudenmann RW. Delusional infestation by proxy--what should veterinarians do? Can Vet J. 2014;55(9):887-891.

33. Bhatia MS, Jhanjee A, Srivastava S. Delusional infestation: a clinical profile. Asian J Psychiatr. 2013;6(2):124-127.

34. Altunay IK, Ates B, Mercan S, Demirci GT, Kayaoglu S. Variable clinical presentations of secondary delusional infestation: an experience of six cases from a psychodermatology clinic. Int J Psychiatry Med. 2012;44(4):335-350.

35. Hinkle NC. Ekbom syndrome: the challenge of "invisible bug" infestations. Annu Rev Entomol. 2010;55:77-94.

36. Munro A. Monosymptomatic hypochondriacal psychosis. Br J Psychiatry Suppl. 1988;2:37-40.

37. Glimcher PW, Rustichini A. Neuroeconomics: the consilience of brain and decision. Science. 2004;306(5695):447-452.

38. Gross-Tsur V, Joseph A, Shalev RS. Hallucinations during methylphenidate therapy. Neurology. 2004;63(4):753-754.

39. Krauseneck T, Soyka M. Delusional parasitosis associated with pemoline. Psychopathology. 2005;38(2):103-104.

40. YehT-C,LinY-C, Chen L-F, etal. Aripiprazole treatment in a case of amphetamine-induced delusional infestation. Aust NZJ Psychiatry. 2014;48(7): 681-682.

41. Spensley J, Rockwell DA. Psychosis during methylphenidate abuse. N Engl J Med. 1972;286(16):880-881.

42. Rosenzweig I, Ramachandra P, Freer J, Wong M, Pieters T. Delusional parasitosis associated with donepezil. J Clin Psychopharmacol. 2011;31(6):781-782.

43. Kölle M, Lepping P, Kassubek J, Schönfeldt-Lecuona C, Freudenmann RW. Delusional infestation induced by piribedil add-on in Parkinson's disease. Pharmacopsychiatry. 2010;43(6):240-242.

44. Aizenberg D, Schwartz B, Zemishlany Z. Delusional parasitosis associated with phenelzine. Br J Psychiatry. 1991;159:716-717.

45. Reilly TM, Jopling WH, Beard AW. Successful treatment with pimozide of delusional parasitosis. Br J Dermatol. 1978;98(4):457-459.

46. Andrews E, Bellard J, Walter-Ryan WG. Monosymptomatic hypochondriacal psychosis manifesting as delusions of infestation: case studies of treatment with haloperidol. J Clin Psychiatry. 1986;47(4):188-190.

47. Srinivasan TN, Suresh TR, Jayaram V, Fernandez MP. Nature and treatment of delusional parasitosis: a different experience in India. Int J Dermatol. 1994;33(12):851-855.

48. Cupina D, Boulton M. Secondary delusional parasitosis treated successfully with a combination of clozapine and citalopram. Psychosomatics. 2012;53(3):301-302.

49. Kansal NK, Chawla O, Singh GP. Treatment of delusional infestation with olanzapine. Indian J Psychol Med. 2012;34(3):297-298.

50. Freudenmann RW, Lepping P. Second-generation antipsychotics in primary and secondary delusional parasitosis: outcome and efficacy. $J$ Clin Psychopharmacol. 2008;28(5):500-508.

51. Bhatia MS, Rathi A, Jhanjee A. Delusional infestation responding to blonanserin. J Neuropsychiatry Clin Neurosci. 2013;25(4):E54.

52. Ponson L, Andersson F, El-Hage W. Neural correlates of delusional infestation responding to aripiprazole monotherapy: a case report. Neuropsychiatr Dis Treat. 2015;11:257-261.
53. Yeh TC, Lin YC, Chen LF, et al. Aripiprazole treatment in a case of amphetamine-induced delusional infestation. Aust $N$ Z J Psychiatry. 2014;48(7):681-682.

54. Altınöz AE, Tosun Altınöz Ş, Küçükkarapınar M, Coşar B. Paliperidone: another treatment option for delusional parasitosis. Australas Psychiatry. 2014;22(6):576-578.

55. Freudenmann RW, Kühnlein P, Lepping $\mathrm{P}$, Schönfeldt-Lecuona C. Secondary delusional parasitosis treated with paliperidone. Clin Exp Dermatol. 2009;34(3):375-377

56. de Berardis D, Serroni N, Marini S, et al. Successful ziprasidone monotherapy in a case of delusional parasitosis: a one-year followup. Case Rep Psychiatry. 2013;2013:913248.

57. Hayashi H, Akahane T, Suzuki H, et al. Successful treatment by paroxetine of delusional disorder, somatic type, accompanied by severe secondary depression. Clin Neuropharmacol. 2010;33(1):48-49.

58. Delacerda A, Reichenberg JS, Magid M. Successful treatment of patients previously labeled as having "delusions of parasitosis" with antidepressant therapy. J Drugs Dermatol. 2012;11(12):1506-1507.

59. Otani K, Miura Y, Suzuki A, Kinoshita O. Effectiveness and safety of milnacipran treatment for a patient with delusional disorder, somatic type taking multiple medications for concomitant physical diseases. Clin Neuropharmacol. 2010;33(4):212-213.

60. Boggild AK, Nicks BA, Yen L, et al. Delusional parasitosis: six-year experience with 23 consecutive cases at an academic medical center. Int J Infect Dis. 2010;14(4):e317-e321.

61. Huber M, Karner M, Kirchler E, Lepping P, Freudenmann RW. Striatal lesions in delusional parasitosis revealed by magnetic resonance imaging. Prog Neuropsychopharmacol Biol Psychiatry. 2008;32(8):1967-1971.

62. Hirjak D, Huber M, Kirchler E, et al. Cortical features of distinct developmental trajectories in patients with delusional infestation. Prog Neuropsychopharmacol Biol Psychiatry. 2017;76:72-79.

63. Freudenmann RW, Kölle M, Huwe A, et al. Delusional infestation: neural correlates and antipsychotic therapy investigated by multimodal neuroimaging. Prog Neuropsychopharmacol Biol Psychiatry. 2010;34(7):1215-1222.

64. Wolf Rch, Huber M, Lepping P, et al. Source-based morphometry reveals distinct patterns of aberrant brain volume in delusional infestation. Prog Neuropsychopharmacol Biol Psychiatry. 2014;48:112-116.

65. Eccles JA, Garfinkel SN, Harrison NA, et al. Sensations of skin infestation linked to abnormal frontolimbic brain reactivity and differences in self-representation. Neuropsychologia. 2015;77:90-96.

66. Huber M, Wolf RC, Lepping P, et al. Regional gray matter volume and structural network strength in somatic vs. non-somatic delusional disorders. Prog Neuropsychopharmacol Biol Psychiatry. 2018;82: $115-122$.

67. Wong S, Bewley A. Patients with delusional infestation (delusional parasitosis) often require prolonged treatment as recurrence of symptoms after cessation of treatment is common: an observational study. Br J Dermatol. 2011;165(4):893-896.

68. Ahmed A, Bewley A. Delusional infestation and patient adherence to treatment: an observational study. Br J Dermatol. 2013;169(3):607-610.
Psychology Research and Behavior Management

\section{Publish your work in this journal}

Psychology Research and Behavior Management is an international, peerreviewed, open access journal focusing on the science of psychology and its application in behavior management to develop improved outcomes in the clinical, educational, sports and business arenas. Specific topics covered in the journal include: Neuroscience, memory and decision making; Behavior
Dovepress

modification and management; Clinical applications; Business and sport performance management; Social and developmental studies; Animal studies. The manuscript management system is completely online and includes a very quick and fair peer-review system, which is all easy to use. Visit http://www. dovepress.com/testimonials.php to read real quotes from published authors. 